\title{
Analysis on the Organizational Structure of Shandong Apple Industry Based on SCP Paradigm
}

\author{
Kai Liu, Fuyu Lv* \\ School of Management, Sichuan University of Science \& Engineering, Zigong, China \\ Email: 1490304171@qq.com, *lfy1105@163.com
}

How to cite this paper: Liu, K., \& Lv, F. Y. (2021). Analysis on the Organizational Structure of Shandong Apple Industry Based on SCP Paradigm. Open Journal of Business and Management, 9, 1572-1584. https://doi.org/10.4236/ojbm.2021.94085

Received: May 17, 2021

Accepted: July 2, 2021

Published: July 5, 2021

Copyright $\odot 2021$ by author(s) and Scientific Research Publishing Inc. This work is licensed under the Creative Commons Attribution International License (CC BY 4.0).

http://creativecommons.org/licenses/by/4.0/

(c) (i) Open Access

\begin{abstract}
Based on the development status of the apple industry in Shandong Province, using the SCP paradigm to analyze the market structure, market behavior and market performance of the apple industry in Shandong Province, it is found that the organizational structure of the apple industry in Shandong Province mainly has the following problems: The apple industry in Shandong Province is relatively low in concentration and the phenomenon of small-scale in production and operation is widespread. Most of the apples are late-maturing and fresh products, and the degree of product differentiation is low; sales channels are narrow; cooperatives have a low level of organization and lack of leading enterprises. Therefore, the planting area and variety structure should be adjusted to optimize the market structure; the promotion channels and the scope of cooperation should be broadened, and innovation capabilities should be improved to improve market behavior, thereby improving market performance.
\end{abstract}

\section{Keywords}

SCP Paradigm, Apple Industry Industrial, Industrial Organization Structure

\section{Introduction}

Shandong Province is a traditional apple producing province. The average yield from 2001 to 2007 was 6,499,600 tons, ranking first among all provinces. The development of its apple industry has played an important role in meeting domestic and international apple demand, improving the structure of Shandong's agricultural planting industry, and increasing farmers' income. However, there are many industrial organizational structure problems in the apple industry in 
Shandong Province, which restrict the sustainable development of the apple industry in Shandong. To this end, this paper uses SCP as a theoretical paradigm to analyze the organizational structure of Shandong's apple industry with a qualitative method, in order to provide academic support and decision-making reference for improving the variety structure, enhancing market performance, and strengthening the Shandong apple industry.

\section{Literature Review}

The SCP analysis framework was initiated by the Harvard school and developed by schools such as Chicago. It consists of three parts: market structure, market conduct, and market performance. Among them, market structure refers to the composition of market entities in a specific industry and their mutual relationships, including market concentration, product differentiation, and entry and exit barriers; market behavior refers to a series of actions taken by market entities to obtain profits and competitive advantages. Including production and operation management, industrial organization adjustment, advertising and publicity; market performance refers to the industry reflects benefit status with a specific market structure through a series of market behaviors, in terms of price, output, cost, profit, product quality, variety, and technological progress. Figure 1 shows the relationship between these three being causal and influencing each other.

At present, the research on the apple industry, scholars mostly analyze the development status of the apple industry, industrial efficiency, supply-side reforms, and conversion of new and old kinetic energy in administrative regions. my country's apple industry is facing problems such as high production costs, low fruit quality, unreasonable variety structure, and prominent contradiction between supply and demand (Chen et al., 2019; Wang et al., 2018). Zhang (2016) analyzed the status quo of the apple industry in Tongchuan City from

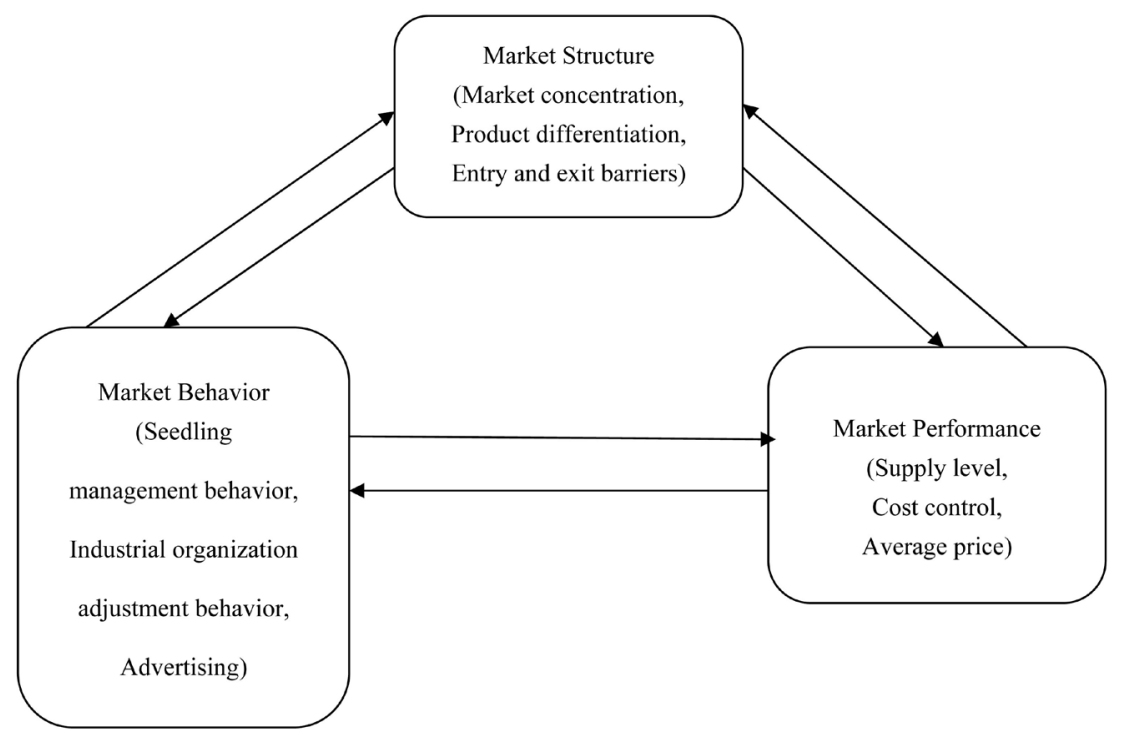

Figure 1. SCP industrial organization structure. 
the aspects of technology, talent, information, and trading platform. Some studies have shown that the production efficiency of the Apple industry still needs to be improved (Zhang et al., 2017; Feng et al., 2017). Scholars have also made useful explorations on the supply-side structural reform of the Apple industry. Strengthen orchard management, market environment construction, and policy support (Sun et al., 2019). Other scholars put forward suggestions to promote the development of the apple industry from the perspective of the conversion of new and old kinetic energy (Zhu \& Liu, 2019; Chen et al., 2019). However, there are few research results using the SCP theoretical paradigm to analyze the apple industry. Jia \& Zhang (2015) used the SCP theoretical framework to study the apple industry and analyzed the problems in the apple industry in Gansu, but failed to find a solution from the causal relationship of the SCP paradigm. Therefore, this article explores the field and puts forward reasonable suggestions from the inherent logic of the SCP paradigm, in order to provide a theoretical reference for the development of the apple industry in Shandong Province.

\section{Analysis on Market Structure of Apple Industry in Shandong Province}

\subsection{Market Concentration}

Market concentration measures the relative size of the market entities of a certain industry, and is divided into buyer's market concentration and seller's market concentration. The author mainly discusses the latter. The concentration of seller's market is usually measured by the Industry concentration (CRn) or Hirschman Index (HHI) in academic circles. The key calculation step of industry concentration is to use the proportion of the market share of the top $\mathrm{N}$ market entities in a specific market. The market share can be expressed in terms of planting area, number of employees, and output. For the convenience of data, planting area is used to measure market share. According to information from the Department of Agriculture and Rural Affairs of Shandong Province, Yantai City, as the largest apple producing area in Shandong Province, has 588 fruit cooperatives and 100 family farms in 2020, with an apple planting area of 2.8 million mu and an output of 5.75 million tons. According to the planting area of the top 8 cooperatives and agricultural enterprises in Table 1 , it is estimated that CR $4=5.76 \%$ and CR $8=7.55 \%$. It can be seen from this that the concentration of the apple industry in Shandong Province is relatively low, and the phenomenon of decentralized production and operation is widespread.

\subsection{Product Differentiation}

Market entities (mainly enterprises) adopt various methods to differentiate products from their competitors in terms of quality, function, packaging, service, 
Table 1. The planting area of the main body of the apple market in Shandong Province.

\begin{tabular}{cc}
\hline Enterprises/Cooperatives & Planting area (mu) \\
\hline Qixia Defeng Apple Professional Cooperative & 60,000 \\
Lonture Co., Ltd. & 43,590 \\
Quanyuan Group & 37,800 \\
Boshida Cooperative & 20,000 \\
Yantai Lian lei Food Co., Ltd. & 20,000 \\
Yantai City Mumu Fruit Industry Professional Cooperative Association & 20,000 \\
Zhaoyuan Fukai Fruit Professional Cooperative & 6000 \\
Yantai Xiange Fruit Professional Cooperative & 4000 \\
\hline
\end{tabular}

Source: Department of agriculture and rural affairs of Shandong province.

and sales channels in order to achieve the goal of occupying a favorable position in the market. The author mainly analyzes the differences of apple products in Shandong Province from the three aspects of variety, brand and sales channels.

1) Variety differentiation

Different varieties of apples have differences in quality and taste, which enable consumers to meet their unique consumer needs. At present, the irrational structure of apple varieties in Shandong Province is mainly manifested in two levels: the structure of planted varieties and the structure of product processing. First of all, the main varieties are diversified. $70 \%$ of the apple planting area and output in Shandong belong to the Red Fuji varieties, but the proportion of early and mid-maturing varieties is low. Early maturity accounts for close to $5 \%$, mainly including Shanxia and Gala series; middle maturity is $10 \%-15 \%$, involving series such as Red General, Mingyue and Jinshuai; late maturity is close to $80 \%-85 \%$, with Red Fuji and Small Guoguang and other products being the main products (Zhu \& Liu, 2018). Secondly, there is a lack of high value-added products, mostly fresh primary products, while the supply of high value-added processed products (such as apple juice, cider, etc.) is scarce. It can be seen that the degree of differentiation of apple varieties in Shandong Province is not high.

2) Brand differentiation

Brand is the foundation for products to win consumer trust, occupy market share and sustainably develop. Strengthening brand building can explore new value growth points, expand the popularity of regional brands among consumer groups, and broaden the profit margin of the Apple industry. According to statistics from the Department of Agriculture of Shandong Province, Yantai Apple became a well-known trademark in China in 2011. In 2014, Yantai issued the "Apple" stamp for the first time and began the selection of the Apple brand. Qixia City was awarded the only "Top Ten Internationally Famous Landmark Brands in the National Fruit and Vegetable Industry" in the apple-growing area. In 2019, the Apple brand values of Yantai and Qixia were 14.148 billion yuan and 6.2 billion yuan. The development of Weihai's apple brand is relatively slow. 
There are currently 154 "three-product" certified fruit products in the city. Well-known corporate brands mainly include "Zhuguo", "Huang Fatzi", and "Hanpin". In 2010, Yishui apples obtained the National Geographical Indication Certification for Agricultural Products, and in 2014 they were awarded the title of "Famous Chinese Fruit". It can be seen that the brand influence of Yantai Apple is more significant than that of Weihai and Linyi, and the brand value difference of the three is more obvious.

3) Differentiation of sales channels

The current supply of Apple can meet the needs of consumers, showing a phased oversupply situation (Cheng \& Zhao, 2019). Diversified sales channels can increase the income of fruit farmers, reduce the risk of unsalable apples, and stimulate the enthusiasm of fruit farmers to plant. Yantai Apple's sales channels are relatively diversified, including direct offline sales by fruit growers, online platform sales, acquisitions by fruit merchants and leading companies, and unified sales by cooperatives (Liang \& Wan, 2019). Among them, the purchase of fruit distributors is currently the main channel for the sale of Yantai apples. For example, Qixia apple sales include online sales and market sales, but online sales account for a relatively low proportion, mainly relying on wholesale market sales (Liu \& Xu, 2020). Linyi apples are mostly primary products packed in plastic boxes and are sold by fruit distributors (Wang et al., 2020). The penetration rate of online sales is relatively low and the sales method is relatively simple. Online sales will be the main direction for the development of sales channels in each apple production area in Shandong in the future, but the current degree of differentiation of sales channels is still not obvious.

\subsection{Entry and Exit Barriers}

1) Barriers to Entry

Entry barriers refer to the disadvantages of potential entrants relative to incumbents. Apples have a relatively slow growth and fruiting period and a long recovery period. Potential entrants lack the ability to resist market price fluctuations and natural risks, resulting in higher opportunity costs for fruit farmers to engage in other industries or plant other crops. Secondly, as the rural labor force shifts to non-agricultural fields, the age structure of apple growers is imbalanced and the aging is more serious. At present, the apple industry is in a period of integration of labor-intensive, capital-intensive and technology-intensive development (Ma \& Huo, 2019), and the cultivation and cultivation of apples puts forward higher requirements on technology and management. Fruit growers should have the corresponding management capabilities and technical level, including the effects of preventing and controlling pests and diseases, the proportion of fertilizers and pesticides, the methods of pruning branches and grafting fruit trees, etc. For growers with serious aging conditions, the requirements for technical management capabilities inhibit their enthusiasm for planting fruit trees. 


\section{2) Barriers to Exit}

Exit barriers refer to the losses caused when the incumbents withdraw from an industry. The Apple industry has been slow to withdraw funds from circulation, and the initial investment is large, and the phenomenon of lock-in is obvious. The withdrawal of fruit farmers from the apple industry means that they have to cut down the planted fruit trees, which not only requires high labor costs, but also the input of various elements for many years has become a sunk cost, which constitutes a cost barrier for fruit farmers to withdraw. In addition, apple enterprises' assets are highly specific, such as sorting, cold storage and other equipment, which also hinder apple enterprises' exit.

\section{Analysis on Market Behavior of Apple Industry in Shandong Province}

\subsection{Seedling Management Behavior}

The quality of seedlings directly affects the quality of the fruit, and it has a significant impact on the sales of the fruit, the improvement of profits, and the building of the brand. At present, self-employment occupies a dominant position in seedling breeding. There are insufficient seedling cultivation enterprises with a certain production scale and a lack of leading enterprises, resulting in a lack of uniform standards for seedling quality and difficulty in ensuring the purity of varieties. For example, the seedling breeding technology in Yantai City has not yet reached the market requirements, and the seedling varieties have a high degree of homogeneity. The enterprises mainly sell "Fuji" bud varieties, which is hardly conducive to updating and optimizing the variety structure (Wang et al., 2019).

\subsection{Industrial Organization Adjustment Behavior}

The organizational adjustment behavior of the Apple industry involves horizontal and vertical adjustments. Horizontal adjustment refers to the organization of small-scale and decentralized small-scale farmers in the form of cooperatives to integrate the purchase of agricultural materials, technical training, and product sales to reduce the costs and risks of decentralized operations of small-scale farmers. When Xin et al. (2019) investigated the Apple cooperatives in Qixia City, they found that most cooperatives have insufficient funds, lack of operational capabilities, and narrow service areas, covering only lowlevel cooperative businesses such as technical information services and primary agricultural product sales. Most members of cooperatives have weak awareness of observation and learning, lack of ability to integrate resources, and their ability to respond to, prevent and control risks needs to be improved. The current sales model is still waiting for buyers to come to purchase, and cannot better meet the needs of modern consumers to purchase products efficiently and conveniently.

Vertical adjustment refers to the integration of production, processing, and 
sales into an organizational system to reduce transaction costs and increase corporate profits, thereby enhancing the competitiveness of the company in the market. The vertical merger of leading enterprises is a typical business model of vertical integration. The author collects and organizes information on leading fruit companies provided by the Department of Agriculture and Rural Affairs of Shandong Province. As shown in Table 2, Shandong Province has now formed a full industrial chain from seedling production to product processing and sales, but there are still a small number of leading companies and insufficient processing enterprises. There are two national-level enterprises, whose business scope involves fruit pulp, canned food and juice processing; and there are nine provincial-level enterprises, which involve base planting, purchase orders, production and processing, and domestic and foreign trade. Leading enterprises show the characteristics of a small number.

\subsection{Advertising}

Advertising is an important way for companies to expand their visibility and gain market share. Yantai City promotes its brand through traditional media. Since 2014, Yantai City has held an Apple production and sales matchmaking meeting, which has broadened the channels for Apple brand companies to cooperate with sales platforms. Shandong Provincial Department of Agriculture, Yantai Municipal Bureau of Agriculture, and Yantai Apple Association participated in organizing fruit companies to participate in large-scale events such as the ASEAN Expo and the Asia-Europe Expo. Carrying out Apple brand selection activities, holding international expositions, and joint exhibitions and promotion meetings between urban areas. These actions have greatly promoted the increase of Apple's brand influence. The Linyi Yishui Apple Cultural Festival and the Apple Arena Exhibition Competition were held in 2018. The establishment of regional brands has increased the public's awareness of Yishui Apples.

\section{Analysis on Market Performance of Apple Industry in Shandong Province}

In view of the availability of data, this article evaluates the market performance of the Shandong Apple industry from three aspects: supply level, cost control, and average price.

Table 2. Leading fruit enterprise in Shandong Province.

\begin{tabular}{ccc} 
Class & Number & Business Scope \\
\hline National class & 2 & Pulp, canned food, juice processing \\
Province class & 9 & $\begin{array}{r}\text { Base planting, order purchase, production and } \\
\text { processing, domestic and foreign trade }\end{array}$ \\
\hline
\end{tabular}

Source: Department of agriculture and rural affairs of Shandong province. 


\subsection{Supply Level}

It can be seen from Figure 2 that from 2007 to 2018, the apple production in Shandong Province showed an overall upward trend. The growth rate of apple production has declined since 2013, so 2013 can be used as a dividing point and the period can be divided into two stages. The first stage is from 2007 to 2013 , and the apple production grows steadily. The second stage is from 2013 to 2018. In 2010, the output of apples fluctuated and fluctuated slightly. Due to the rise of the apple industry in various regions and the decline in fruit prices, fruit farmers in some areas of Shandong Province planed trees and destroyed orchards, and the reduction in planting area caused fluctuations in apple production. In addition, the change of apple cultivation mode in Shandong Province and the excessive number of aging orchards have also caused a decline in apple production.

\subsection{Cost Control}

Figure 3 demonstrates the changing trend of planting costs since 2007, showing that labor is no longer the driving force for output growth, and high labor costs have also squeezed out the profits of fruit farmers. Although chemical fertilizers and pesticides can increase yields, the cost is still relatively high, and irregular fertilization and pesticide using by fruit farmers occur from time to time, which not only increases production costs, but also is harmful to the improvement of apple quality.

\subsection{Average Price}

Figure 4 shows the average selling price of apples in Shandong Province from 2007 to 2018. Apple prices fluctuate greatly. The price of apples from 2008 to 2009 was affected by the global financial crisis, and the increase was limited;

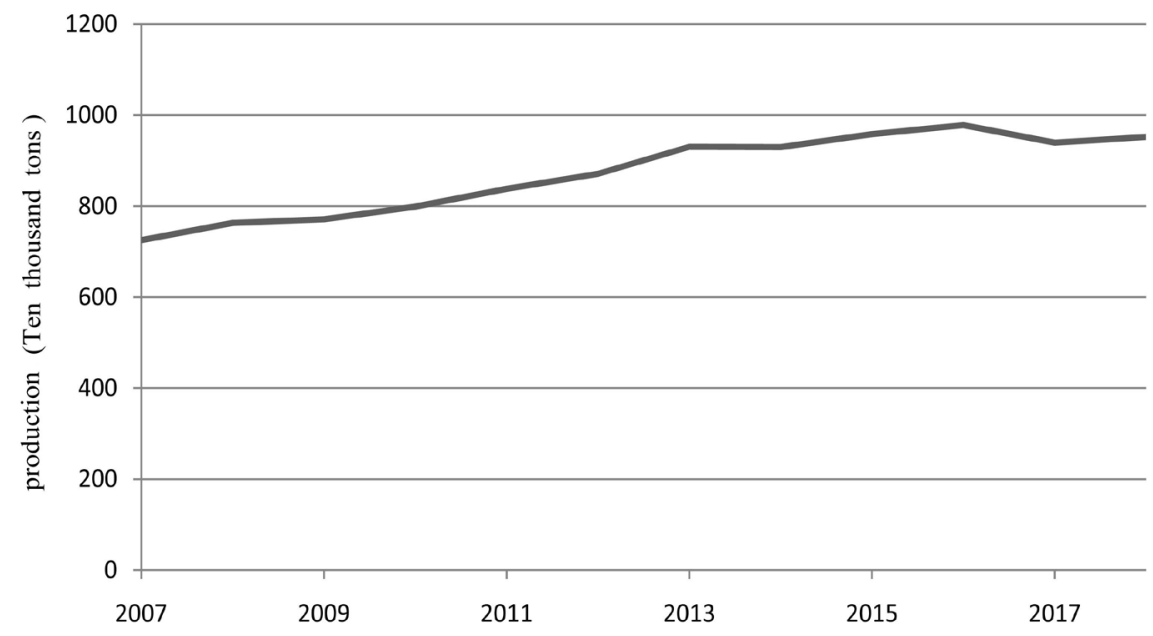

Figure 2. The change trend of apple production in Shandong Province. Source: "National agricultural product cost-benefit data compilation". 


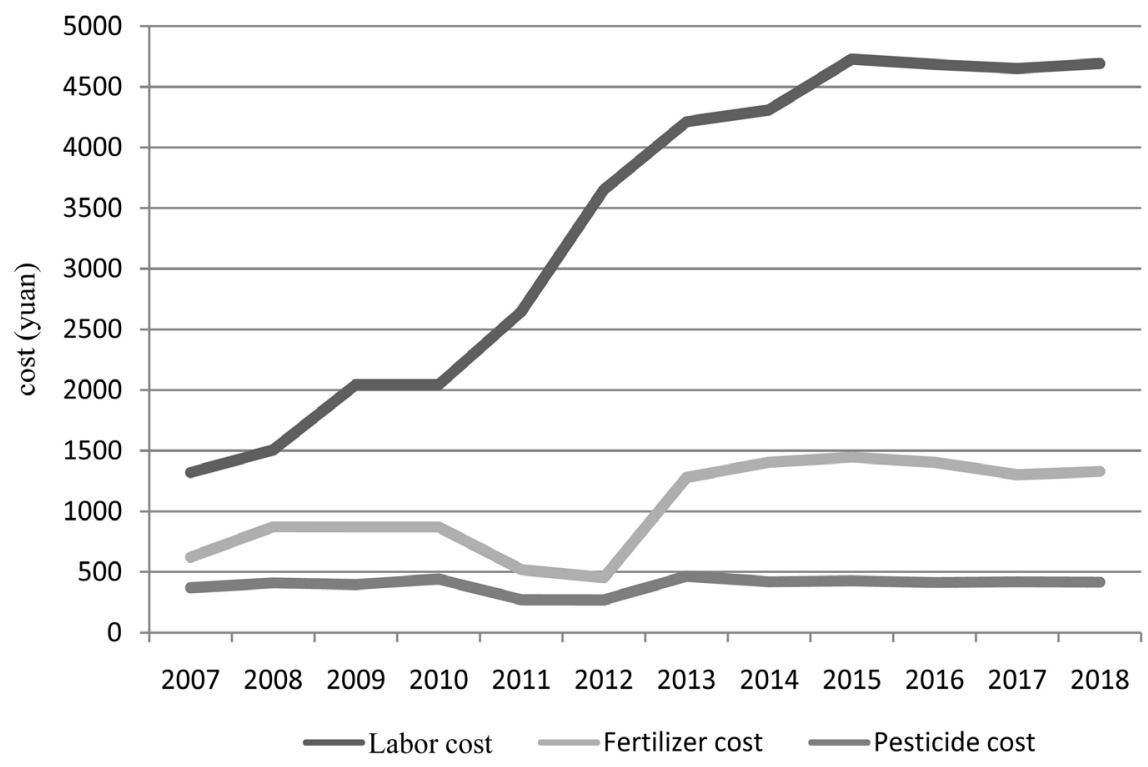

Figure 3. The change trend of apple cost in Shandong Province. Source: "National agricultural product cost-benefit data compilation".

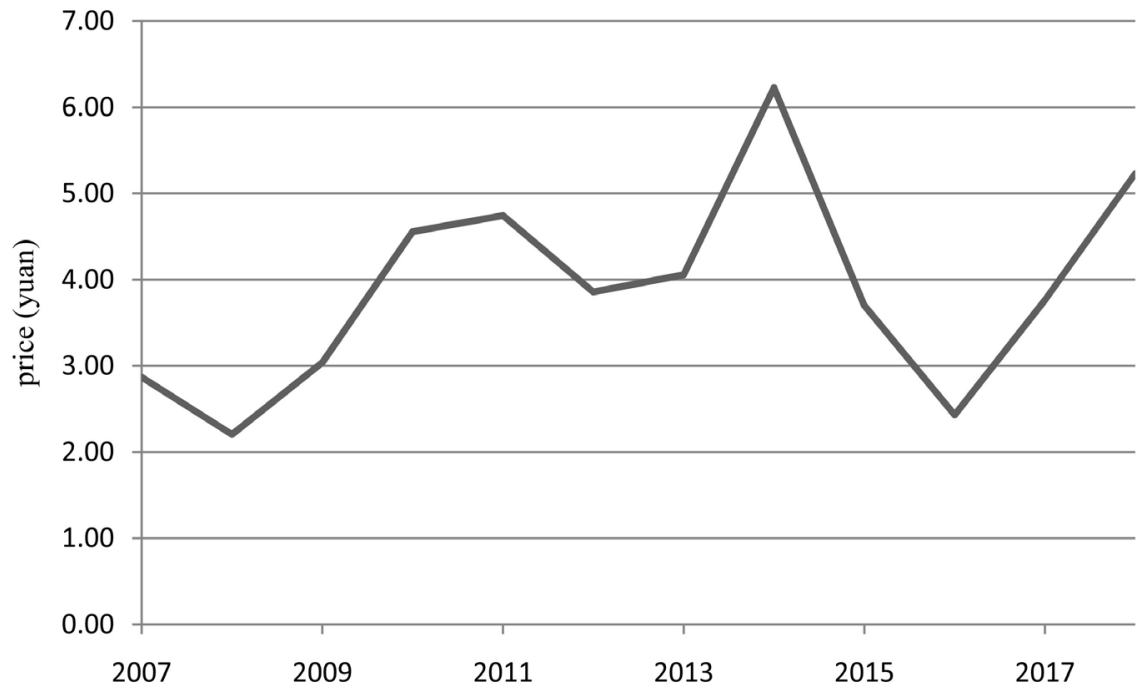

Figure 4. The change trend of the average price of apples in Shandong Province. Source: "National agricultural product cost-benefit data compilation".

from 2009 to 2011, due to increased investment in agricultural materials and technologies, the price of apples showed a growth trend; since 2011, the increase in apple production has led to the price drops; From 2012 to 2014, the market demand was strong, consumers' purchasing power increased, and the price of apples rose steadily; after 2014, the supply of apples exceeded demand, the market was sluggish, and the proportion of good quality apples was low, which led to price declines. It started to pick up in 2016. In general, the high-quality apple fruit rate in Shandong Province is not high, and the price of apples is greatly affected by market conditions. 


\section{Suggestions on Optimizing the Organizational Structure of Apple Industry in Shandong Province}

\subsection{Optimize the Planting Area and Promote the Centralized Operation of the Industry}

The production of high-quality apples requires suitable geographical climate, soil conditions and standardized management. First, optimize the layout of apple planting areas. Promote the transfer and concentration of apple planting to areas with sufficient sunshine and mild climate, so as to promote the improvement and enhancement of apple appearance, taste and quality. Second, increase soil cultivation and protection. Apples need to grow in a soil environment with a certain thickness, air permeability and rich organic matter. However, in recent years, the soil has deteriorated and fertility has declined. Therefore, the soil should be improved and soil protection measures should be artificially implemented to create a suitable soil environment for the growth of apples. Finally, promote the construction of the Apple Standard Park. Apple Standard Park has the ability to purchase advanced agricultural technology and talents with scientific management knowledge, and can carry out detailed and appropriate management in irrigation, plastic surgery, and pest protection. At the same time, scientific and standardized production can promote the reduction of production management costs, improve the efficiency of the production process of the orchard, and improve the quality of fruit, thereby effectively connecting to the market of consumption upgrades.

\subsection{Adjust the Variety Structure to Improve Product Differentiation and Diversification}

Optimize the types and processing structure of apples and increase the diversity of products to meet the diverse needs of consumers. First, optimize the structure of apple types. Combine market consumption conditions, integrate resources, increase early and mid-maturing varieties, and adjust the ratio of early, mid-to-late maturity, so as to subdivide the consumption market space and alleviate the problem of concentrated time to market caused by too many late-maturing varieties. Second, optimize the processing structure of apples. In addition to the use of fresh food, apples can also be made into products with high added value, such as apple flavor, dried apples, apple cider, apple cider vinegar and canned apples. Increasing the proportion of Apple's deep processing can not only increase product sales, but also increase the profits of Apple processors, thereby promoting the transformation and upgrading of the Apple industry.

\subsection{Broaden Publicity and Sales Channels to Create a Diversified, Multi-Level Sales Model}

Make full use of the advantages of the Internet to build multi-channel marketing. First, increase efforts to popularize Internet advantages to farmers and train 
farmers to use the Internet for publicity and sales. The Internet has the characteristics and advantages of rich information transmission, fast transmission speed, and wide transmission range, which can effectively increase the audience for product promotion. Through popularization and training to farmers in the village community, publicity and sales can be improved. Secondly, use short videos and live broadcasts to bring goods for sale. Use the new sales model to promote and sell Apple through sharing platforms and celebrity effects, shorten the distance between consumers and producers, and even production scenarios, and enhance consumers' understanding and trust in product production processes and quality, thereby enhancing Apple's market Competitive advantage and increasing the benefits of fruit farmers and manufacturers.

\subsection{Cultivate Cooperatives and Leading Enterprises and Improve the Level of Cooperation and Innovation Capabilities}

Enhance the trust of cooperatives and realize the full coverage of the cooperative's business scope from raw material procurement to product sales, thereby reducing the production costs of fruit farmers, and giving full play to the advantages of cooperation in procurement, management and sales. First, purchase raw materials and agricultural materials unifily. Purchasing raw materials and agricultural materials with cooperatives as the main body can not only enhance the voice of negotiation, reduce procurement costs, but also unify the quality and specifications of apple varieties and agricultural materials. Second, train management skills unifily. The growth of apples requires fruit farmers to have scientific management knowledge. Cooperatives can provide learning and training opportunities to help farmers rationally use agricultural production materials to reduce costs and increase profits. Finally, publicize production unifily. Cooperatives can take advantage of the advanced platform to promote and sell their apples, and they can use cooperatives or even cooperatives as a unit for sales, which can increase the income of farmers and promote the sustainable development of the apple industry in Shandong Province.

Enhance the government's role in supporting leading enterprises and improve their innovation capabilities. Leading companies have the financial resources to conduct research on varieties, technologies, and management. They can hire high-end R \& D talents or cooperate with relevant research institutions to research and develop new varieties, use Internet technology to supervise production workers, and use cloud computing, big data and other technology to carry out data collection, data analysis and terminal control during production process, so as to save production costs, ensure quality standards, and improve fruit quality.

\section{Funding}

Social science key research base of Zigong City federation of social sciencesIndustrial transformation and innovation research center's funded project (Item 
number: CZ21E01).

\section{Conflicts of Interest}

The authors declare no conflicts of interest regarding the publication of this paper.

\section{References}

Chen, H., Wang, Q., \& Gao, Q. (2019). Analysis of My Country's Apple Industry Development and Its Influencing Factors-Based on Panel Data of seven Major Producing Provinces. Chinese Fruit Tree, No. 1, 92-95.

Chen, X. S., Mao, Z. Q., Wang, N., Zhang, Z. Y., Wang, Z. G., Jiang, S. T. et al. (2019). My Opinion on the Conversion of the New and Old Kinetic Energy of the Fruit Tree Industry in My Country IV: To Serve the Revitalization of the Countryside, the Research on Fruit Tree Resources and Breeding Must Adhere to Both Theoretical and Technological Innovation and the Matching of Good Varieties and Methods. Chinese Fruit Tree, No. 6, 1-5.

Cheng, C. G., \& Zhao, D. Y. (2019). The Development Position and Trend of My Country's Apple Industry in the New Situation. Chinese Fruit Tree, No. 1, 1-7.

Feng, X. L., Liu, M. Y., \& Huo, X. X. (2017). Research on Total Factor Productivity of Chinese Apples under Carbon Emission Constraints. Journal of China Agricultural University, 22, 157-168.

Jia, H., \& Zhang, Y. R. (2015). Research on the Organization of Apple Industry in Gansu Province Based on SCP Analysis. Journal of Gansu Institute of Public Administration, No. 4, 97-102+128.

Liang, Q., \& Wan, T. T. (2019). Research on Optimization of Marketing Channels in Yantai Apple Industry. Think Tank Era, No. 17, 50+75.

Liu, S., \& Xu, X. L. (2020). The Problems and Countermeasures of Qixia Fruit Farmers' Apple Sales in the Internet Era. Agricultural Outlook, 16, 138-143.

Ma, X. D., \& Huo, X. X. (2019). Apple Standardized Production, Regulatory Effects and Improvement Suggestions-Based on the Survey and Analysis of 960 Apple Growers in 11 Counties in Shandong, Shaanxi and Gansu Provinces. Agricultural Economic Issues, No. 3, 37-48.

Sun, J. J., Yan, W. J., \& Guo, L. (2019). Analysis on the Supply-Side Structural Reform Mechanism of China's Apple Industry. Northern Horticulture, No. 21, 135-141.

Wang, C. H., Chen, D. S., \& Wang, Y. (2019). Suggestions on the Layout and Structure Optimization of Apple Industry in Yantai City. Chinese Fruit Tree, No. 6, 101-105.

Wang, X., Liu, J. D., Shao, L. Q., Yan, Z. Y., Han, M. Y., \& Huo, X. X. (2018). The Annual Development Status of My Country's Apple Industry and Its Trends and Suggestions. Chinese Fruit Tree, No. 3, 101-104+108.

Wang, Z. L., Wang, J., Liu, L. J., Zhang, J. J., Liu, Y. G., \& Cui, X. M. (2020). The Development Status and the Countermeasures to Improve Its Quality and Efficiency of the Apple Industry in Linyi City. Anhui Agricultural Sciences, 48, 229-231.

Xin, X. J. (2019). Investigation and Research on the Development of Apple Specialized Cooperatives in Qixia City, Shandong. Yantai: Yantai University.

Zhang, F. H., Huo, M., Song, X. L., \& Wang, H. Y. (2017). Spatial Agglomeration Analysis of Production Efficiency in Main Apple Producing Areas in China Based on SBM and Malmquist Index. Agricultural Technology Economy, No. 5, 57-66. 
Zhang, X. Q. (2016). Research on the Development of Apple Industry in Tongchuan City. China's Agricultural Resources and Regionalization, 37, 197-201+210.

Zhu, H. Y., \& Liu, X. Z. (2018). Analysis and Countermeasures of the Problems Existing on the Supply Side of Apple Industry-Taking Shandong Province as an Example. Forestry Economy, 40, 67-70.

Zhu, H. Y., \& Liu, X. Z. (2019). Research on the Conversion of New and Old Kinetic Energy of China's Apple Industry-Based on C-D Yield Function Model. Arid Land Resources and Environment, 33, 61-67. 